\title{
Article \\ Geochemical Analysis of Two Samples of Bitumen from Jars Discovered on Muhut and Masirah Islands (Oman)
}

\author{
Jacques Connan ${ }^{1, *(D)}$, Michael H. Engel ${ }^{2}$, Robert B. Jackson ${ }^{3} \mathbb{D}$, Seth Priestman ${ }^{4}$, $\operatorname{Tom}_{\text {Vosmer }}{ }^{5}$ \\ and Alex Zumberge ${ }^{6}$ (D)
}

1 Laboratoire de Biogéochimie Moléculaire, Institut de Chimie, Université de Strasbourg, 23 rue Antoine de Saint-Exupéry, 64000 Pau, France

2 School of Geosciences, The University of Oklahoma, 100 East Boyd Street, Norman, OK 73019-1009, USA; ab1635@ou.edu

3 Independent Researcher, 40 Whalen Road, Randolph Center, Randolph, VT 05061, USA; rbjackson181@gmail.com

4 Department of Archaeology, Durham University, South Road, Durham DH1 3LE, UK; Priestman@gmail.com

5 Department of Maritime Archaeology, Western Australian Museum, Cliff St., Fremantle, WA 6160, Australia; tom@muheet.com.au

6 GeoMark Research Inc., 9748 Whithorn Drive, Houston, TX 77095, USA; alex.zumberge@gmail.com

* Correspondence: connan.jacques@orange.fr

Citation: Connan, J.; H. Engel, M.; Jackson, R.B.; Priestman, S.; Vosmer, T.; Zumberge, A. Geochemical Analysis of Two Samples of Bitumen from Jars Discovered on Muhut and Masirah Islands (Oman). Separations 2021, 8, 182. https://doi.org/ 10.3390 /separations 8100182

Academic Editor: César Oliveira

Received: 2 September 2021

Accepted: 30 September 2021

Published: 12 October 2021

Publisher's Note: MDPI stays neutral with regard to jurisdictional claims in published maps and institutional affiliations.

Copyright: (C) 2021 by the authors. Licensee MDPI, Basel, Switzerland. This article is an open access article distributed under the terms and conditions of the Creative Commons Attribution (CC BY) license (https:/ / creativecommons.org/licenses/by/ $4.0 /)$.
Abstract: Two samples of bitumen were obtained, one from a torpedo jar (c. 3rd-8th C. AD) from Masirah island and one from a Tunisian jar (c. 18th C. AD) from Muhut island off the central coast of Oman. Steranes and terpanes, as well as isotope data on chromatographic fractions, were used as tools to characterize the bitumen. Comparison of data with those already acquired on bitumen from torpedo jars from Thailand, Iran, Indonesia, Sri Lanka, Saudi Arabia, India, and oil seeps from Iran and Iraq allowed us to conclude that the bitumen originated from different areas of southwest Iran. Those of the Muhut jar were likely from Khuzistan, whereas those from Masirah island appear to have been sourced from Kermanshah. These findings are in keeping with other similar geochemical studies undertaken on bitumen lined vessels from across the region (see more below).

Keywords: Oman; Tunisia; torpedo jar; bitumen; Muhut island; Masirah island; biomarkers; steranes; terpanes; carbon and deuterium isotopes

\section{Introduction}

Geochemical analyses (carbon and deuterium isotope ratios of chromatographic fractions, steranes, and terpanes) were performed on two samples scraped from jars discovered on the nearby islands of Masirah and Muhut off the central coast of Oman (Figure 1). The analyses confirmed the presence of bitumen in both cases. The main objective of this research was to determine the source of the bitumen. Was it of local origin (Yemen?) or imported? If the bitumen was imported from distant regions, is there any relationship between the origin of the jars and the origin of bitumen? How do the bitumen origins match the known trade routes during this historical period? For that purpose, the results obtained were compared to previous data available on bitumen from torpedo jars collected in Thailand, Iran, Indonesia, Sri Lanka, Saudi Arabia, India, and on modern oil seeps from Iran and Iraq [1-4]. The origin of bitumen on jars brings some insight into the trade routes of the Indian Ocean and documents the commercial exchange networks that took place between the c. 3rd and 18th centuries AD. 


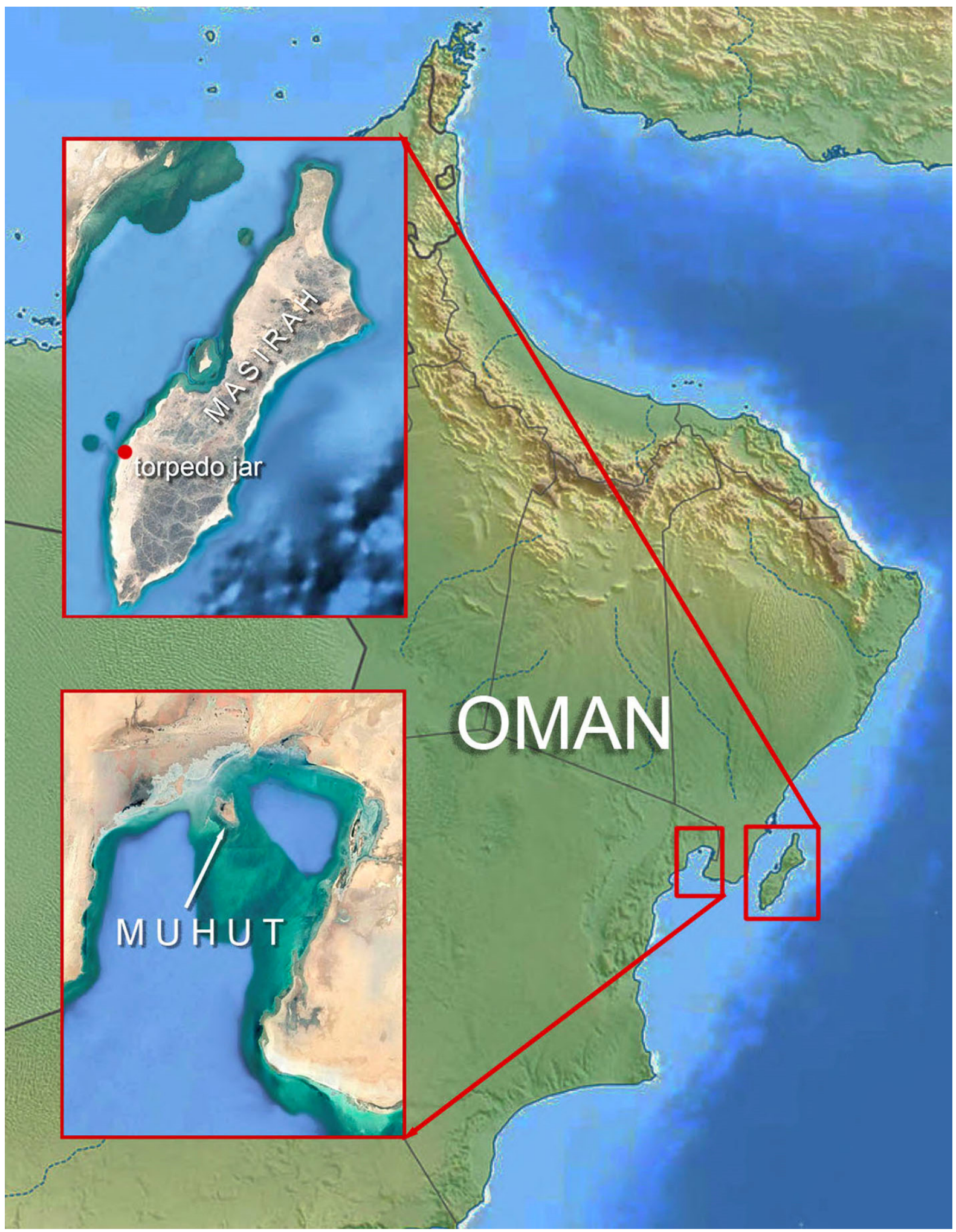

Figure 1. Location of the Muhut amphorae and of the Masirah torpedo jars.

\section{Materials and Methods}

2.1. Archaeological Samples

The samples were provided by Khamis bin Saeed bin Humaid Al Asmi, Director of the Department of Excavation and Archaeological Studies of the Ministry of Heritage and Tourism, Muscat, Sultanate of Oman. The first jar, stored in the Ministry of Heritage and 
Tourism and referred to here as the Muhut amphora, came from Jazirat Muhut (alternatively Mahout, Mahawt) (Figure 2). It is one of a collection of large, complete, and chronologically related storage/transportation jars from the island, including: (a) sefri, (b) nosfi, and (c) jriba, all from Djerba, Tunisia, (d) Julfar ware from Ras al-Khaimah ([5] (pp. 70-76, Figure 25) and (e) grey gritty ware, part of a fairly well known regional complex of the late Islamic period, which appear in a variety of forms (see [6] (pp. 10-11), Figures 7 and 8). Of the amphorae, the sefri and jriba types are known to still be produced on the island of Djerba in Tunisia. Julfar ware and grey gritty ware were produced in the northern Arabian Peninsula at least into the mid-20th century.

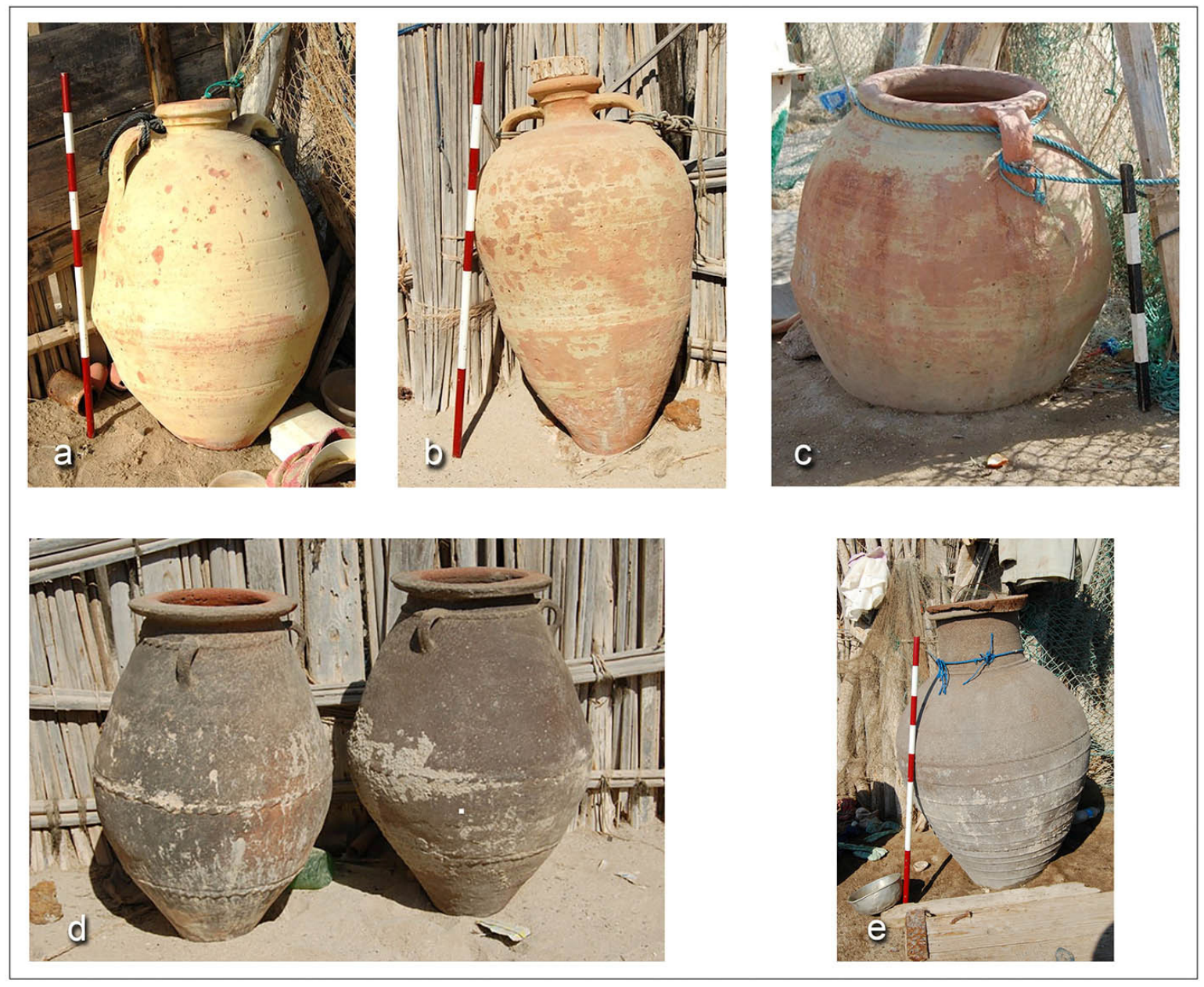

Figure 2. Types of amphorae and storage jars from Muhut island: (a) sefri type, (b) nosfi type, (c) jriba type, (d) Julfar ware, (e) grey gritty ware.

The amphora from which the bitumen was sampled is a Tunisian vessel of the sefri type (Figure 2a). According to Empereur [7], this type developed in the 18th century. It is nearly identical in form to amphorae still produced on the island of Djerba today ([8] (p. 89), and observations made by R. Jackson during a 2014 visit to Djerba). In addition to those in the Muhut collection, other intact examples of sefri amphorae discovered south of the Mediterranean include one in Djibouti, two in Eritrea ([9] (p. 36), and three in the Monastery of St. Paul at Ras Ghareb in Egypt (observed by R. Jackson).

Muhut island, which measures only 2.6 by 1.5 kilometres, is covered by low mangrove forests on its northern, western, and southern shores. More than a hundred modest dwellings and fishing shacks constructed of barasti palms, mangrove branches, and planks salvaged from wooden boats dot the sandy portion of the island's eastern shore. Although the island once supported a permanent population of people from the Al-Hakmani tribe, 
today local fishermen inhabit it only seasonally. They fish and harvest sea cucumbers that fetch high prices on the Asian market. Numerous sea turtle shells scattered along the beaches of Muhut attest to the regular harvesting of sea turtles for their meat, which is likely consumed locally.

Muhut holds the remains of several Omani cargo badans (Figure 3), a traditional sailing vessel formerly used for trading between southern Arabia, East Africa, and, sometimes, the Gulf. Inhabitants of Muhut stated, in 2009, that the amphorae had been used for carrying fresh water aboard ships. However, although the jars might have contained water while on board, such use was likely an anomaly for ships at sea. Indeed, it is well documented that traditional wooden ships of the Indian Ocean carried drinking water in wooden cisterns called fintās. Additionally, if trading ships routinely carried water in amphorae, one would expect their remains to be far more common in the many ports of Arabia and Africa, but this is not the case. Of the imported Djerban amphorae, only those few examples mentioned above, plus a few scattered shards, have been discovered outside Oman (and south of the Mediterranean). Thus, it seems likely that the Muhut amphorae, which were used originally to transport olive oil in the Mediterranean, were brought to the waterless island and repurposed for storing water that the inhabitants laboriously carried over from the mainland. Given an amphora's capaciousness (approximately 150-170 litres for a sefri), portability (when empty), and great durability, it is hard to imagine a more suitable container for such an essential task.

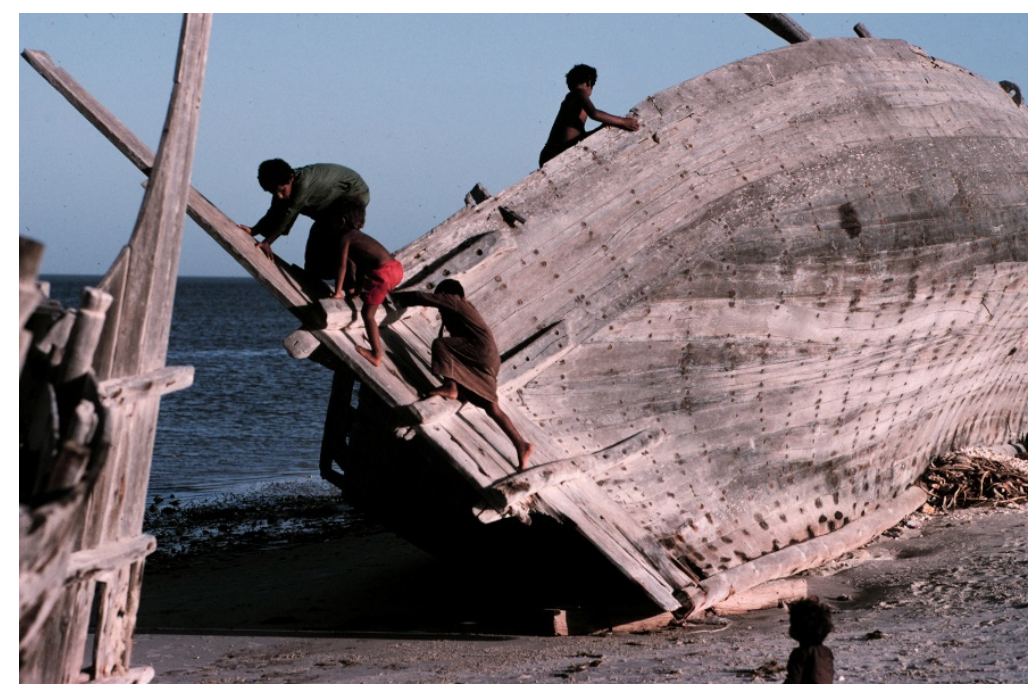

Figure 3. Children play on abandoned cargo badans on. Muhut island. Photo courtesy of Roger Garwood.

Although the fabrics of the Muhut amphorae have not yet been analysed, their typology confirms their Djerban provenance. The bitumen sample used in this study was collected from the exterior of the only amphora in the Muhut collection that bore traces of the material. Given that no bitumen was found on the interior surface of the amphora, it is possible that the sample taken from the exterior surface was related to the process of sealing the mouth of the vessel (Figures 4 and 5). 


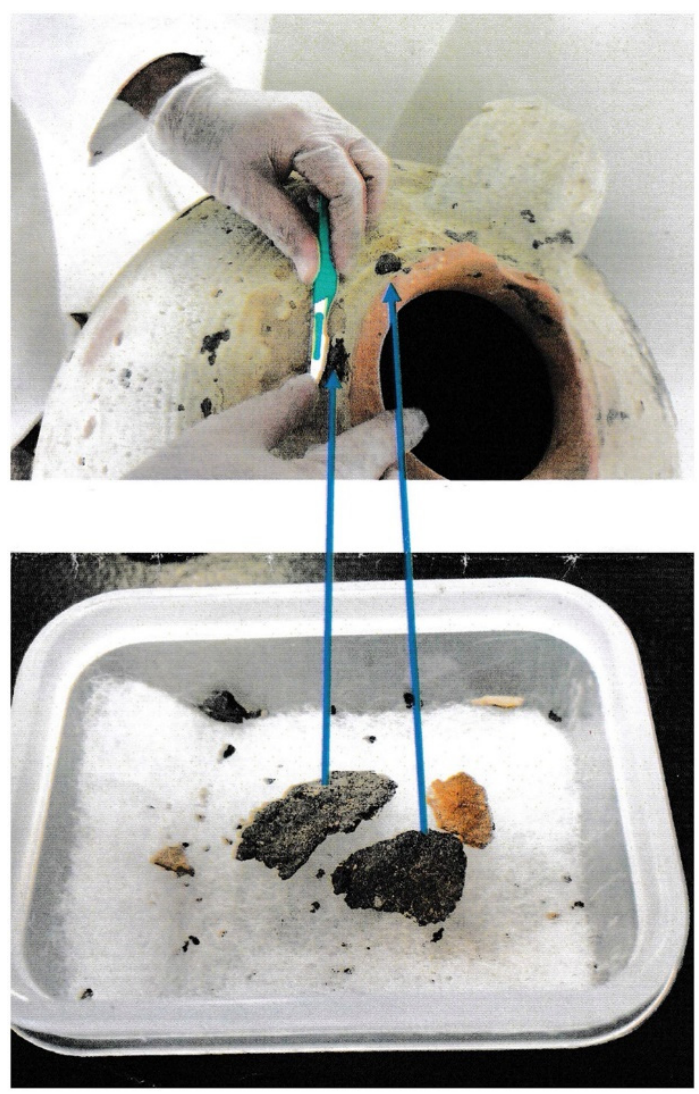

Figure 4. Sampling bitumen from the Muhut amphora (@ Ministry of Heritage and Tourism, Sultanate of Oman.
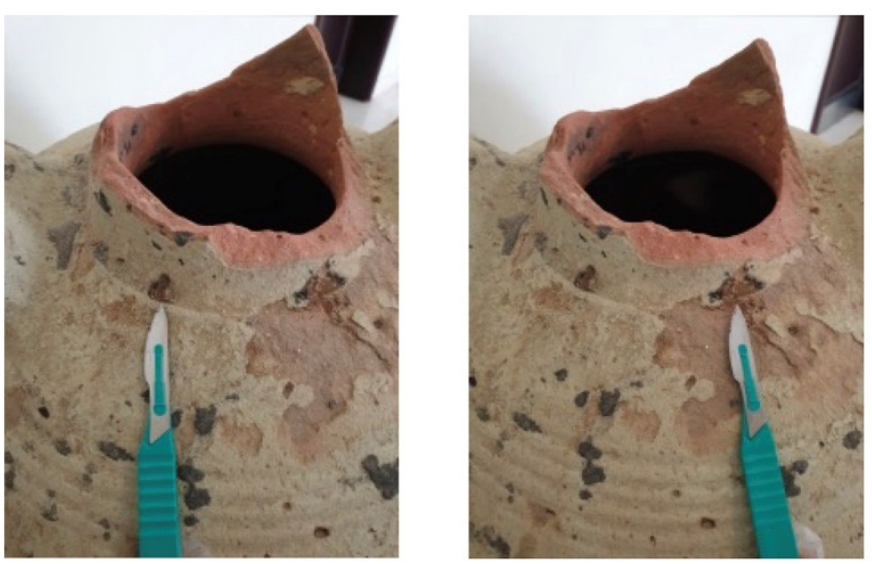

Figure 5. Sampling sites of the Muhut amphora ( Ministry of Heritage and Tourism).

The second vessel (DA7383, Figures 6 and 7), displayed in the National Museum of Oman, came from Masirah Island, where it was discovered in near-complete condition alongside a second, almost identical, vessel (DA7384) on a beach near Maraib (or Mayrab) on the southwest coast of the island (Figure 1) ([10] (pl. 7); [11] (pp. 86, 98, Figures 174, 206)). A label accompanying the jars, written in 1984, recorded that they were discovered on the surface after a hurricane (cyclone) in 1977. The cyclone dropped nearly 17 inches $(430 \mathrm{~mm})$ of rain on Masirah Island in $24 \mathrm{~h}$ which, combined with sand erosion by storm waves, is believed to have exposed the vessels on the beach. 


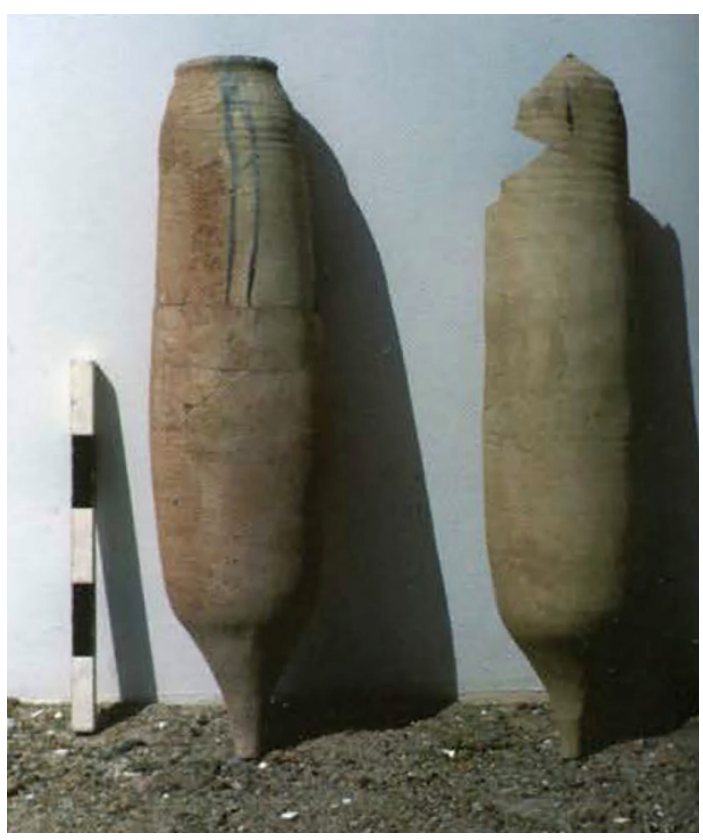

Figure 6. The two torpedo jars DA7383 and DA7384 following discovery on Masirah Island (after Weisgerber and Al-Shanfari 2013, Figure 174).

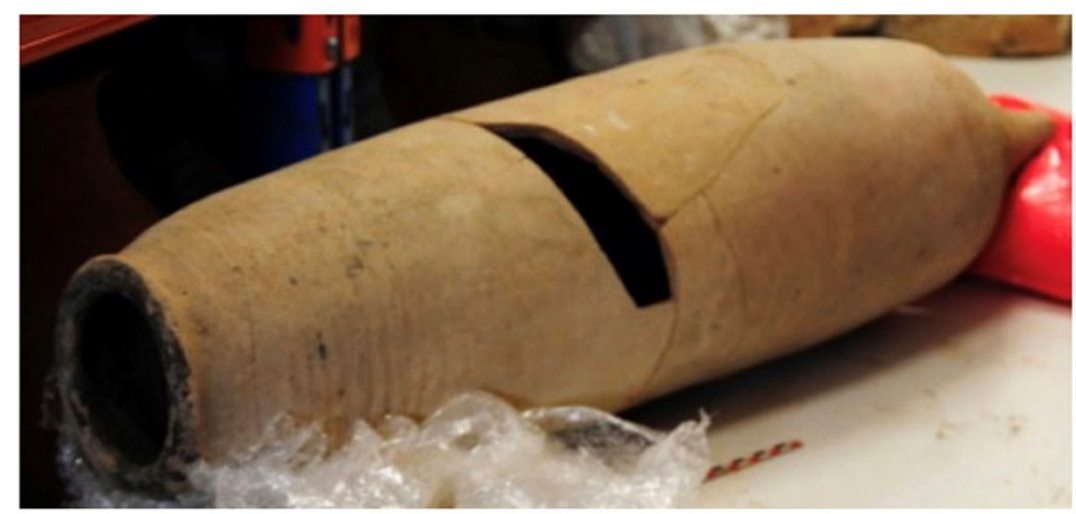

Figure 7. The torpedo jar from which the sample was taken. Image courtesy of Seth Priestman.

The vessels had a tall cylindrical form, a pointed elongated base with a squared foot, and simple rolled rim. Pronounced ribbing extending across the neck, shoulder, and upper body indicate that at least the upper portion was wheel thrown. The vessels were, respectively, $90.5 \mathrm{~cm}$ and $96 \mathrm{~cm}$ tall with a maximum diameter of $20.5 \mathrm{~cm}$, indicating carrying capacities of 20 and 24 litres, or weights when full of c. $27.2 \mathrm{~kg}$ and $31.6 \mathrm{~kg}$ (calculated by Patrick Couser using the volumetric suite of MaxSurf naval architecture software). The fabric of the vessels was buff coloured and sandy and the interior was coated with a thick bitumen lining with splashes running onto the outside.

Though the fabric has not been directly analysed, the combined evidence of the fabric appearance, bitumen lining, and vessel forms clearly indicates that both are characteristic examples of earlier sandy torpedo jar type, referred to as TORP-S ([12] (pp. 41-42, pl. 18, Figures 162, 165: a-g)). Such vessels are of particular interest as their form and waterproof lining demonstrates their intended use in the waterborne transportation of bulk liquid commodities. The vessel type is, therefore, especially closely associated with the activity of the Indian Ocean maritime trade. The class represents an important proxy for the archaeological reconstruction of ancient trade networks within the region.

There is a growing body of recently published research related to torpedo jars and the full details regarding their function, dating, provenance, and archaeological associations 
will be only briefly summarised here ([1,13-15]). The archaeological distribution of torpedo jar finds throughout the western Indian Ocean reinforces their evident association with maritime exchange activity. Examples have been recovered from several sites in East Africa, southern and eastern Arabia, throughout the Gulf and across the lowlands of central and southern Mesopotamia/southwest Iran, and many sites, particularly along the west coast of India and Sri Lanka. The easternmost known examples come from the two examples of sewn-plank tradition shipwrecks discovered in Southeast Asia: the late 8th century Phanom-Surin wreck in Thailand ([16] (pp. 185, 187, Figures 9 and 10)) and the mid-9th century Belitung wreck in Indonesia ([17] (pp. 646-647, No. 294)). There is growing evidence to suggest that torpedo jars were the primary receptacle for the containment, transportation, and serving of wine. However, most of the available evidence is tangential and further research on this topic is required. Vessels may also have been used for multiple purposes or their function transformed through reuse, as is evidently the case with the frequent use of jars as ossuaries on the Bushehr peninsula in southern Iran ([18]).

Chronologically, torpedo jars represent a long-lived tradition that makes their archaeological interpretation somewhat problematic. It is evident that they emerge as a distinct category from a more ancient tradition of narrow-mouthed, bitumen-lined vessels with ovoid bodies that likely performed a similar function in the transportation of wine and circulated widely across the Gulf region during the later centuries BC/early centuries AD ([15]). The precise point of transition from "ovoid jars" to recognisable "torpedo jars" requires further investigation. However, the difference is marked by clear changes in vessel morphology and the replacement of a coarse organic tempered fabric with one containing profuse, well-sorted, mixed sandy inclusions. The earliest examples of TORP-S can probably be dated to the 3rd century. Finds remained common on sites across the Gulf during subsequent centuries throughout the Sasanian and early Islamic periods. There is emerging, and now fairly clear, evidence to indicate that TORP-S was increasingly replaced, or supplemented, by a new category with a different cream-coloured fabric and distinct typological characteristics (TORP-C) from around the mid-8th century ([12] (pp. 42-44, pl. 17, Figure 164)). However, it is not yet clear if both categories continued to circulate together, or if one replaced the other. The production of all varieties does not appear to extend beyond the 9 th century. It is hoped that via further research, it will be possible to recognise more precise, and perhaps chronologically constrained, varieties of torpedo jar productions. Details related to rim and base profiles do not show much obvious variation. Instead, one potential element of consideration is the overall vessel profile and mode of vessel formation, which is best studied in the form of complete examples. In this respect, the distinct cylindrical form of the vessels from Masirah represent a useful case type, which is very clearly different from the more bulbous forms frequently associated with a number of Sasanian period sites in southern Mesopotamia, such as Telūl Hamediyāt ([19] (Figures 3; 5-6; 7: 11, 16, 18, 21-23; 8: 32-33; 9: 36-39; 14; 15: 1)) or Umm Keshm ([20] (p. 217, Figures 4-7)). It is hoped that, in time, the typological variant from Maraib will enable a closer dating.

Recent petrographic and geochemical analysis of the clay fabric and bitumen lining of torpedo jars, and isotopic analysis of the latter, point firmly to a source for their production within southwest Iran, with some possible minor variation indicating different locations of production across this wider area $([1,13,21])$. Again, the associations between different material compositions and typological variation offer a further important avenue for investigation. The current analysis presented here forms part of a wider scientific investigation of torpedo jars from multiple sites, the results of which remain under analysis and forthcoming. Finally, in respect of the Masirah vessels, the find context and condition of the vessels appears potentially significant. Fragmentary examples of torpedo jars are common from coastal settlements of the Sasanian and early Islamic period within the Gulf area, including sites such as Kadhima ([22] (pp. 16-17, Figure 3)), Sir Bani Yas ([23] (p. 85-86, Table 2, Figures 13: 1-6, 8-10; 19: 10-11)), and Jazirat al-Hulaylah ([24] (Figures 46: 95-184 L.4; 49: 95-163 L.1, 95-205 L.1, 95-151 L.2)). By contrast, complete vessels have so far 
mostly been recovered in association with burials (see above) and shipwrecks ([25]). The examples from Masirah appear to have occurred in complete isolation. They are not, as far as one can ascertain, associated with any other ceramic finds indicative of contemporary settlement in this area. Furthermore, no such site has so far been detected from more recent surveys within the vicinity $([26,27])$. While Weisgerber and Al-Shanfari specifically dismissed the possibility of the vessels having been washed ashore intact from a nearby shipwreck ([11] (p. 86)), another credible possibility seems to be that they represent the remains of a beached shipwreck that was subsequently covered by dune formation. The specific area of recovery clearly warrants further investigation. More broadly, the vessels represent typical examples of maritime transport containers, most likely exported with their original contents from the head of the Gulf to Oman sometime between the c. 3rd to 8th century AD.

\subsection{Analytical Procedures}

Geochemical and isotopic analysis was undertaken on bitumen samples extracted from the Mahut and Masirah vessels and compared to an extensive modern reference database of samples from Iraq, Iran, and wider areas of the Middle East in order to determine the likely source of the ancient material. All archaeological and geological samples were subjected to the same analytical procedure conducted at GeoMark Research Ltd. The dichloromethane extract $(\mathrm{EO}=$ extractable organic matter in \%/weight of whole sample) was deasphalted using n-hexane. The desasphalted supernatant was separated into saturated hydrocarbons (sat), aromatic hydrocarbons (aro), and resins (NSO) (compounds bearing nitrogen, sulphur, and oxygen) using gravity flow column chromatography employing a 100-200 mesh silica gel support activated at $400{ }^{\circ} \mathrm{C}$ prior to use. Hexane was used to elute saturated hydrocarbons, methylene chloride to elute the aromatic hydrocarbons, and methylene chloride/methanol (50:50) to elute the NSO fraction. Following solvent evaporation, the recovered fractions were quantified gravimetrically. The $\mathrm{C}_{15+}$ saturated hydrocarbon fraction was subjected to molecular sieve filtration (Union Carbide S-115 powder, Uniin carbide Corporation, Texas, TX, USA) after the technique described by West et al. ([28]). An aliquot of the total alkane fraction was not fractionated by silicalite in order to preserve access to the n-alkanes.

Gas chromatography mass spectrometry (GC-MS) of the $\mathrm{C}_{15+}$-branched and cyclic hydrocarbon fractions was performed using an Agilent 7890A (split injection) (Agilent Technologies, Wilmington, DE, USA)interfaced to an Agilent 5975C mass spectrometer (Agilent Technologies, Stevens Creek Boulevard Santa Clara, CA, USA). The HP-2 column $\left(50 \mathrm{~mm} \times 0.2 \mathrm{~mm}, 0.11 \mu \mathrm{m}\right.$ film thickness) was temperature programmed from $150{ }^{\circ} \mathrm{C}$ to $325^{\circ} \mathrm{C}$ at 2 .

$\mathrm{C} / \mathrm{minute}$ and held for $10 \mathrm{~min}$. The mass spectrometer was run in the selected ion mode (SIM), monitoring ions $m / z$ 177, 191, 205, 217, 218, 231, and 253 amu for branched and cyclic alkanes.

To determine the absolute concentration of individual biomarkers, a deuterated internal standard (d4- $\mathrm{C}_{29 \alpha \alpha \alpha}$ 20Rsterane, Chiron lab, Norway) was added to the $\mathrm{C}_{15+-}$ branched/ cyclic hydrocarbon fraction. Response factors (RF) at 221 for the deuterated standard to hopane $(m / z 191)$ and sterane $(m / z 217)$ authentic standards were found to be 1.4 for terpanes and 1.0 for steranes. Concentrations of individual biomarkers were determined using the following equation: Conc. $($ in ppm $)=($ Ht biomarker $)($ ng standard $) /($ Ht standard $)(\mathrm{RF})$ (mg B/C fraction).

The $\mathrm{C}_{15+}$ saturates, $\mathrm{C}_{15+}$ aromatics, asphaltenes, and resins were analysed for their respective carbon isotope $\left(\delta^{13} \mathrm{C}, \mathrm{VPDB}\right)$ compositions. Approximately 200-300 $\mathrm{gg}$ of each sample was loaded and sealed in a tin cup (Costech, Valencia, CA). Samples were placed in sequence in an autosampler mounted on a Costech elemental analyser interfaced through a Conflo III valve with a Thermo Delta V Plus isotope ratio mass spectrometer (Thermo Fisher Scientific, West Palm Beach, FL). The $\delta^{13} \mathrm{C}$ values are reported per mil (\%o) relative to the VPDB standard (uncertainty $\pm 0.1 \%$ ). 
For hydrogen isotope analysis, approximately $300 \mu \mathrm{g}$ of each sample was wrapped in silver capsules (Costech 041066, Valencia, CA, USA), which were placed in sequence in a Costech zero blank autosampler equipped with an isolation valve that was mounted on a Thermo TC/EA high temperature elemental analyser. The furnace reactor column was packed with glassy carbon granulate chips (Thermo 1117400) in accordance with the Thermo TC/EA method. The reactor furnace temperature was $1400{ }^{\circ} \mathrm{C}$ and the GC oven temperature was set at $100^{\circ} \mathrm{C}$. The resulting hydrogen gas sample was carried by a helium stream at a flow rate of $100 \mathrm{~mL} / \mathrm{min}$ to a Thermo Conflo III interface with the dilution on and analysed by a Thermo Delta V Plus isotope ratio mass spectrometer (Thermo Fisher Scientific, West Palm Beach, FL, USA).

After H3+ corrections ([29]), $\delta^{2} \mathrm{H}$ was then reported relative to the VSMOW-SLAP scale as:

$$
\delta^{2} \mathrm{H}=\left[\mathrm{R}\left({ }^{2} \mathrm{H} /{ }^{1} \mathrm{H}\right)_{\mathrm{P}} / \mathrm{R}\left({ }^{2} \mathrm{H} /{ }^{1} \mathrm{H}\right)_{\text {VSMOW }}\right]-1
$$

where $\mathrm{R}\left({ }^{2} \mathrm{H} /{ }^{1} \mathrm{H}\right)_{\mathrm{P}}=\mathrm{N}\left({ }^{2} \mathrm{H}\right)_{\mathrm{P}} / \mathrm{N}\left({ }^{1} \mathrm{H}\right)_{\mathrm{P}}$ is the ratio of the number of ${ }^{2} \mathrm{H}$ atoms to the number of ${ }^{1} \mathrm{H}$ atoms in sample $\mathrm{P}$ and equivalent parameters applied for VSMOW $([30,31])$.

The $\delta^{2} \mathrm{H}$ values were then determined using the standards NBS22 oil $\left(\delta^{2} \mathrm{H}_{\mathrm{VSMOW}}=\right.$ -116.9 per mil, [30]) and IAEA-CH-7 $\left(\delta^{2} \mathrm{H}_{\mathrm{VSMOW}}=-100.3\right.$ per mil, [32] $)$ on the VSMOWSLAP scale, such that $\delta^{2} \mathrm{H}$ of SLAP was -428 per mil relative to VSMOW $([29,30]$; uncertainty $\pm 5 \%$ ).

The analytical flowchart applied to this set of samples was identical to the one described in the recent paper by Connan et al. ([1]).

\section{Results and Discussion}

\subsection{Gross Composition of Dichloromethane Extract}

The gross composition data are presented in Table 1. The gross compositions of the two extracts were different. The bitumen of the Muhut amphora was rather rich in hydro carbons (19.6\%) and showed a moderate concentration of asphaltenes (46.7\%). The bitumen from the Masirah amphora was typical of torpedo jar bitumen and of archaeological bitumen ([33-39]). This bitumen exhibited a very low content of hydrocarbons $(3.7 \%)$ and a predominant concentration of asphaltenes $(87.6 \%)$.

Table 1. Gross composition and isotopic data. Significance of abbreviations: \% extract = \% extractable organic matter with dichloromethane $(\% /$ weight of sample), sat $=$ saturated hydrocarbons, aro = aromatic hydrocarbons, $\mathrm{NSO}=$ resins, asp $=$ asphaltenes.

\begin{tabular}{|c|c|c|c|c|c|c|c|c|c|c|c|c|c|}
\hline $\begin{array}{l}\text { Lab } \\
\text { No. }\end{array}$ & Object & Location & $\begin{array}{c}\% \\
\text { extract }\end{array}$ & $\begin{array}{l}\% \\
\text { sat }\end{array}$ & $\begin{array}{l}\% \\
\text { aro }\end{array}$ & $\%$ NSO & $\begin{array}{l}\% \\
\text { asp }\end{array}$ & $\begin{array}{l}\delta^{13} \text { Csat } \\
\text { (\%o/VPDB) }\end{array}$ & $\begin{array}{c}\delta^{13} \text { Caro } \\
(\% / \text { VPDB })\end{array}$ & $\begin{array}{c}\delta^{13} \text { Cresin } \\
(\% / \text { /VPDB })\end{array}$ & $\begin{array}{c}\delta^{13} \text { Casp } \\
(\% / \text { VPDB })\end{array}$ & $\begin{array}{c}\delta \text { Dresin } \\
(\% / \text { VSMOW) }\end{array}$ & $\begin{array}{c}\delta \text { Dasp } \\
\text { (\%/VSMOW) }\end{array}$ \\
\hline 3284 & $\begin{array}{l}\text { Muhut } \\
\text { am- } \\
\text { phora }\end{array}$ & $\begin{array}{l}\text { Jazirat } \\
\text { Muhut }\end{array}$ & 19.2 & 9.6 & 10 & 33.7 & 46.7 & -27.2 & -26.7 & -26.8 & -28.8 & -115 & -108 \\
\hline 3285 & $\begin{array}{l}\text { Amphora } \\
\text { DA7383 }\end{array}$ & $\begin{array}{l}\text { Masirah } \\
\text { Island }\end{array}$ & 49.4 & 2.2 & 1.5 & 8.7 & 87.6 & -28.4 & -27.6 & -28.1 & -28.0 & -86 & -73 \\
\hline
\end{tabular}

\subsection{Isotope Data}

Carbon isotope data (Table 1) showed a significant difference in the properties of both bitumens. The plot of $\delta^{13}$ Casp (\%o/VPDB) vs. $\delta^{13} \mathrm{CNSO}(\% / \mathrm{VPDB})$ in Figure 8 , by comparison with data from jars of Thaj (Saudi Arabia), SBY9 (Abu Dhabi), PhanomSurin (Thailand), Busher (Iran), Belitung (Indonesia), and various sites in India, clearly differentiated both bitumens. Four oil seeps from Iran (Masjid-i-Soleiman in Khuzistan and Ain Gir, Gel Siah and Mordeh Fel in Kermanshah and Lurestan provinces were added as references in Figure 8, but other references have been published in Connan et al. [1], Connan and Carter [3], and Connan et al. [2]. The Muhut bitumen appears apart from others with isotope values, which suggest an origin in Khuzestan. The Masirah bitumen is more common among bitumen of torpedo jars and has a possible origin in LurestanKermanshah. 


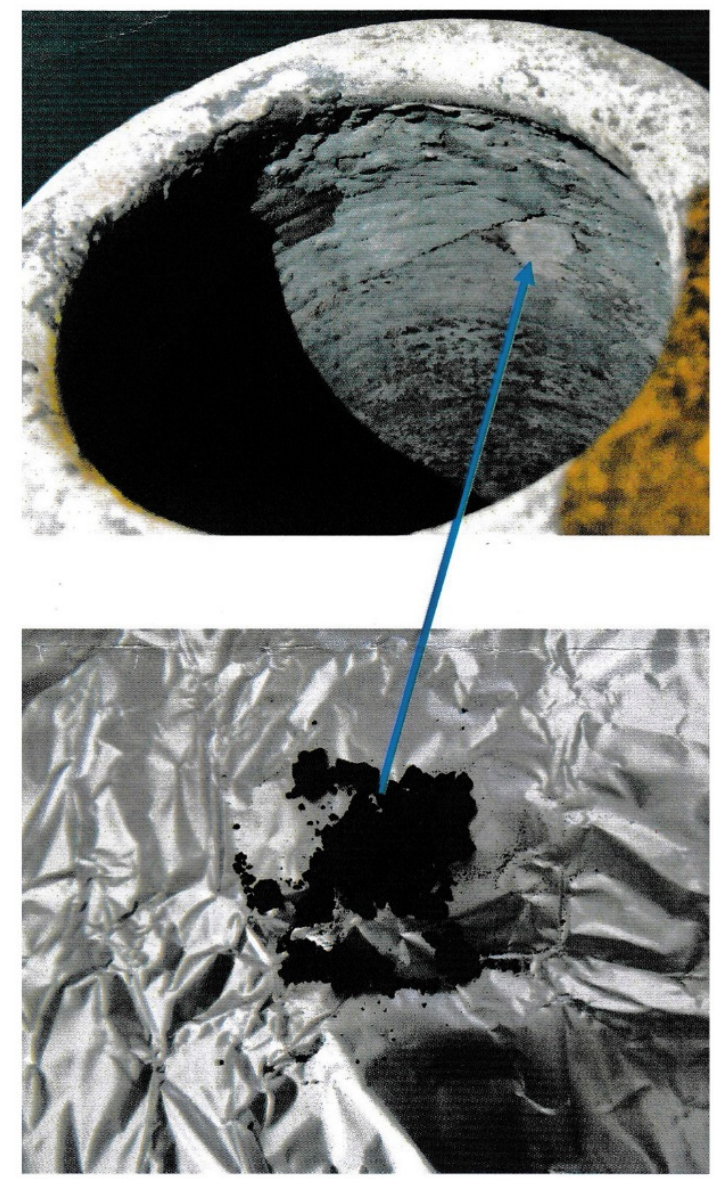

Figure 8. Sampling site and sample of the torpedo jar (@ National Museum, Sultanate of Oman).

Deuterium isotopes of polar fractions agree with the gross composition data. Deuterium values of resins and asphaltenes, respectively of $-115 \%$ and $-108 \%$ /VSMOW, indicated that the Muhut bitumen was not severely affected by oxidation and, in that respect, was rather well preserved, as suggested by the high amount of hydrocarbons. On the contrary, the bitumen from the Masirah amphora was more oxidized, as shown by the deuterium values of resins (NSO) and asphaltenes, respectively, of $-86 \%$ and $-73 \%$ /VSMOW. Such values are currently recorded in torpedo jar bitumen. For instance, samples from Thaj in Saudi Arabia gave average values of $-79 \%$ and $-72 \%$ /VSMOW for resins and asphaltenes.

\subsection{Molecular Chemistry}

Mass fragmentograms of steranes $(m / z 217)$ and terpanes $(m / z 191)$ confirmed the differences already mentioned on the basis of isotopic data (Figure 9). Terpanes of the Muhut bitumen were dominated by the $\alpha \beta$-hopane family, which did not show obvious evidence of biodegradation. Low-molecular-weight tricyclopolyprenanes $(23 / 3,24 / 3,26 / 3)$ were rather low in abundance and probably removed by water washing and evaporation for high members of the family $(28 / 3,29 / 3,30 / 3)$, which were well detected. Ts/Tm was moderate $(0.61$, Table 2$)$ and the $18 \alpha(\mathrm{H})$-oleanane, though in low concentration, was detectable. Steranes were not biodegraded, as seen by the C29 $\alpha \alpha \alpha 20 S / 20 \mathrm{R}$ ratio $=0.71$. As expected, the diasteranes were well represented. All these characteristics agreed with an Iranian bitumen from the Khuzistan area. The terpanes of the Masirah bitumen were dominated by the $\alpha \beta$-hopane family. The Ts/Tm was low (Ts/Tm $=0.16$, Table 2) and no oleanane was present. Steranes were rather well preserved but showed a slight effect of biodegradation on the biological configurations ([40-43]), the $\alpha \alpha \alpha 20 \mathrm{R}$ of C27 and C29 steranes $(C 27 \alpha \alpha \alpha 20 S / C 27 \alpha \alpha \alpha 20 R=2.1$ and C29 $\alpha \alpha \alpha 20 S / C 29 \alpha \alpha \alpha 20 \mathrm{R}=1.08)$. This 
biodegradation was, however, incipient and very limited in regard to similar situations seen elsewhere in archaeological samples (for instance, in bitumens of Kuriki Höyük in Turkey, [44], submitted).

Table 2. Molecular data. Significance of abbreviations: $\mathrm{Ol} / \mathrm{H}=18 \alpha(\mathrm{H})$-oleanane $/ \mathrm{C} 30 \alpha \beta$-hopane; $\mathrm{C} 31 \mathrm{R} / \mathrm{H}=\mathrm{C} 31 \alpha \beta-22 \mathrm{~S}$ hopane; GA/C31R = gammacerane $/ \mathrm{C} 31 \alpha \beta-22 \mathrm{R}$-hopane; Ster $/$ terp = sterane $/$ terpane; Dia $/$ Reg = diasteranes $/$ regular steranes; \%C27 = \% C27 $\alpha \beta \beta$ steranes; \%C28 = \%C28 $\alpha \beta \beta$ steranes; \%C29 = \% C29 $\alpha \beta \beta$ steranes; C2920S $/ \mathrm{C} 2920 \mathrm{R}=$ C29 $\alpha \alpha \alpha 20$ Ssterane/C29 $\alpha \alpha \alpha 20$ Rsterane; $29 \beta \beta S / \alpha \alpha \mathrm{R}=\mathrm{C} 29 \alpha \beta \beta 20$ Ssterane $/ \mathrm{C} 29 \alpha \alpha \alpha 20$ Rsterane, Ts $/ \mathrm{Tm}=\mathrm{Ts}=18 \alpha-22,29$; 30-trisnorneohopane $/ \mathrm{Tm}=17 \alpha$-22,29,30-trisnorhopane.

\begin{tabular}{|c|c|c|c|c|c|c|c|c|c|c|c|c|c|c|}
\hline $\begin{array}{l}\text { Lab } \\
\text { No. }\end{array}$ & Object & $\begin{array}{c}\text { C30 } \\
\text { hopane } \\
\text { (ppm) }\end{array}$ & $\mathrm{C} 29 \mathrm{H} /$ & $\mathrm{HOI} / \mathrm{H}$ & $\mathrm{C} 31 \mathrm{R} / \mathrm{H}$ & GA/C31R & Ster/terp & Dia/Reg & $\% \mathrm{C} 27$ & $\% \mathrm{C} 28$ & $\% \mathrm{C} 29$ & $\begin{array}{c}\text { C29 } \\
\text { 20S/R }\end{array}$ & $\mathrm{C} 29 \beta \beta \mathrm{S} / \alpha \alpha \mathrm{R}$ & $\mathrm{Ts} / \mathrm{Tm}$ \\
\hline 3284 & $\begin{array}{c}\text { Muhut } \\
\text { am- } \\
\text { phora }\end{array}$ & 604 & 0.77 & 0.06 & 0.41 & 0.39 & 0.33 & 0.37 & 30.6 & 30.9 & 39.6 & 0.71 & 1.18 & 0.61 \\
\hline 3285 & $\begin{array}{l}\text { Amphora } \\
\text { DA7383 }\end{array}$ & 4653 & 0.99 & 0 & 0.42 & 0.42 & 0.2 & 0.37 & 32.3 & 25.3 & 42.4 & 1.08 & 1.59 & 0.16 \\
\hline
\end{tabular}

Molecular data are compiled in Table 2. The plot of data in the diagram Ts/Tm vs. $\delta^{13}$ Casp (\% /VPDB), which is currently used to trace the origin of bitumens in archaeological samples, shows that the Muhut bitumen was clearly different from the Masirah bitumen. The Masirah bitumen was similar to several samples analysed from Thaj (Saudi Arabia) (Figure 10). Another diagram, taking into account the ratio $18 \alpha(\mathrm{H})$-oleanane/C $30 \alpha \beta$ Hopane vs. Ts/Tm of Muhut and Masirah bitumens in comparison to values obtained from oil seeps of Iran (Figure 11), allows us to propose Mamatain as the type of source for Muhut bitumen, whereas Masirah matches the bitumen of Emam Hassan, Pol Doktar, Sultan dyke, and Pataq in Kermanshah province (Figure 12). Interestingly Mamatain has also been identified as the likely source of bitumen used to line later-dated cream-coloured torpedo jars of the TORP-C variety ([1]). The continued use of this source into the late Islamic period needs to be further investigated in relation to later settlement activity within the area. 


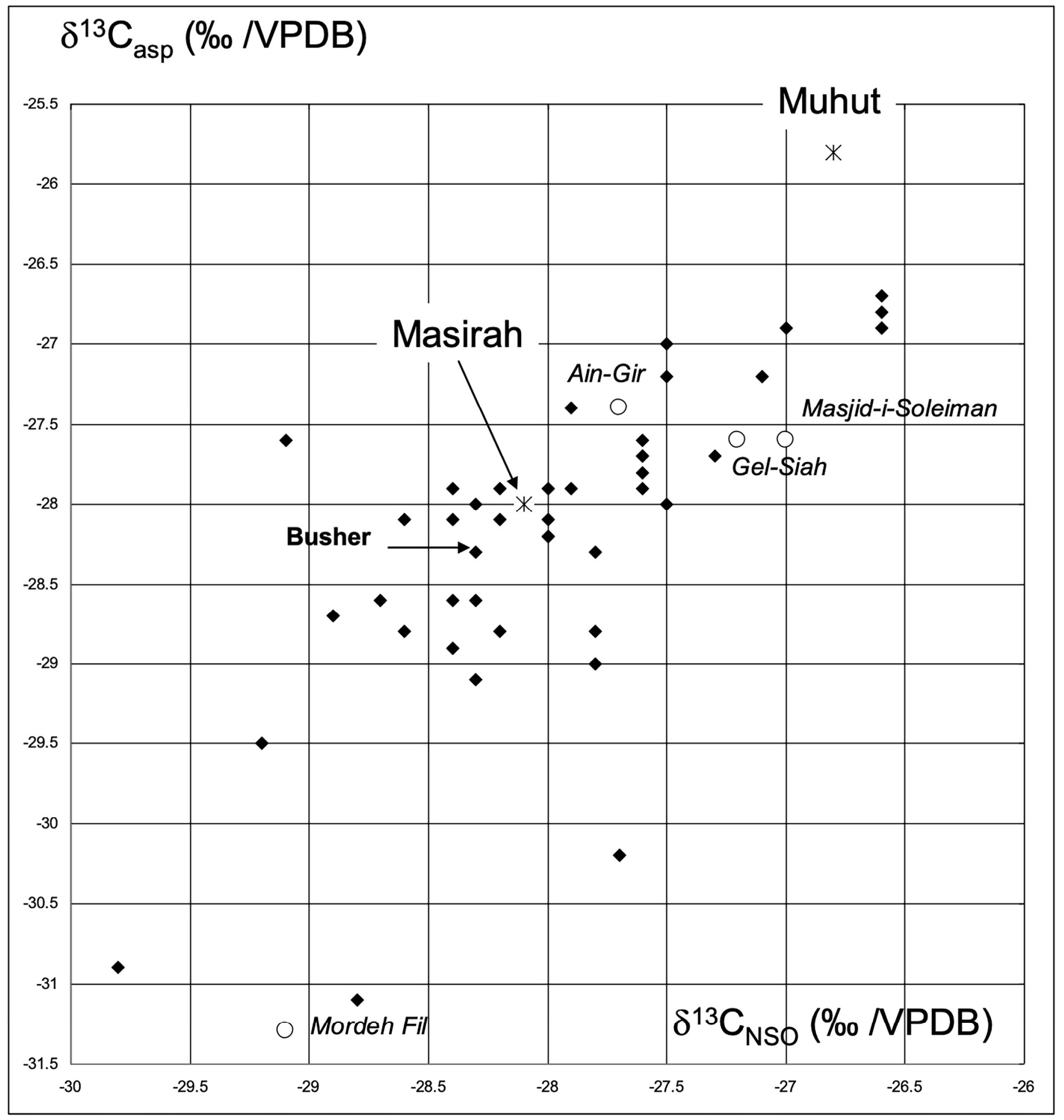

Figure 9. Plot of $\delta{ }^{13} \mathrm{Casp}\left(\%\right.$ /VPDB) vs. $\delta{ }^{13} \mathrm{CNSO}$ (\% /VPDB) from Muhut and Masirah bitumens: comparison with data from other archaeological sites and from four oil seeps of Iran. The archaeological sites are: Thaj (Saudi Arabia), Phanom-Surin (Thailand), Busher (Iran). 

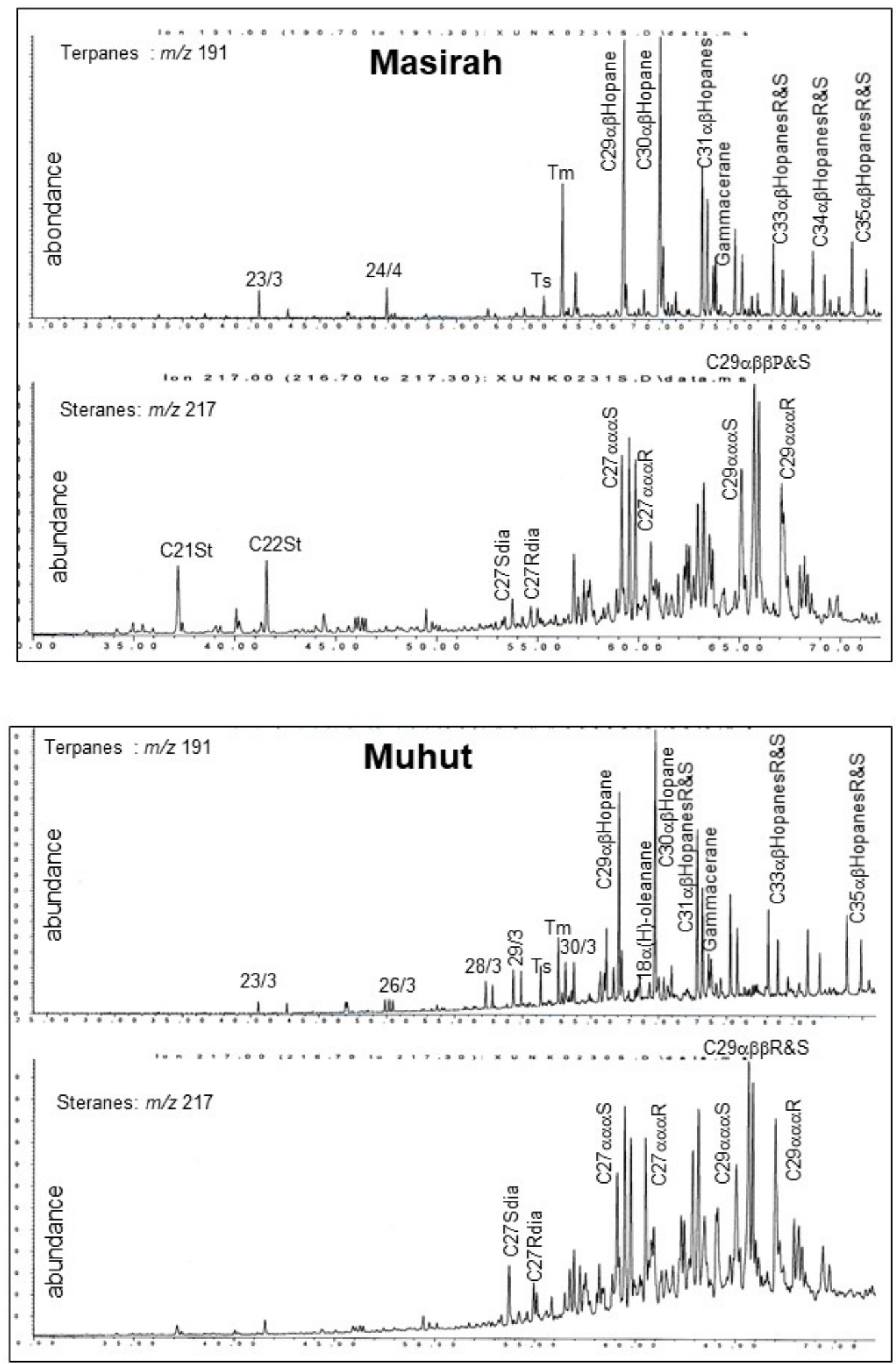

Figure 10. Mass fragmentograms of steranes $(m / z$ 217) and terpanes $(m / z$ 191) from Masirah and Muhut bitumens. Significance of abbreviations: $C 29 \alpha \beta$ hopane $=17 \alpha, 21 \beta$-30norhopane, $C 30 \alpha \beta$ hopane $=17 \alpha, 21 \beta$-hopane, C31 $\alpha \beta$ hopaneR\&S $=17 \alpha, 21 \beta, 22 S \& R-30$-homohopane, $C 35 \alpha \beta$ hopaneR\&S $=17 \alpha, 21 \beta$-22S-29pentakishomohopane, $C 29 \alpha \beta \beta R \& S=5 \alpha, 14 \beta, 17 \beta-$ 20R + 20S-24ethylcholestane, C29 $\alpha \alpha \alpha \mathrm{R}=5 \alpha, 14 \alpha, 17 \alpha$-20R-24-ethylcholestane, Ts $=18 \alpha-22,29 ;$ 30-trisnorneohopane, Tm = $17 \alpha-22,29,30$-trisnorhopane. 


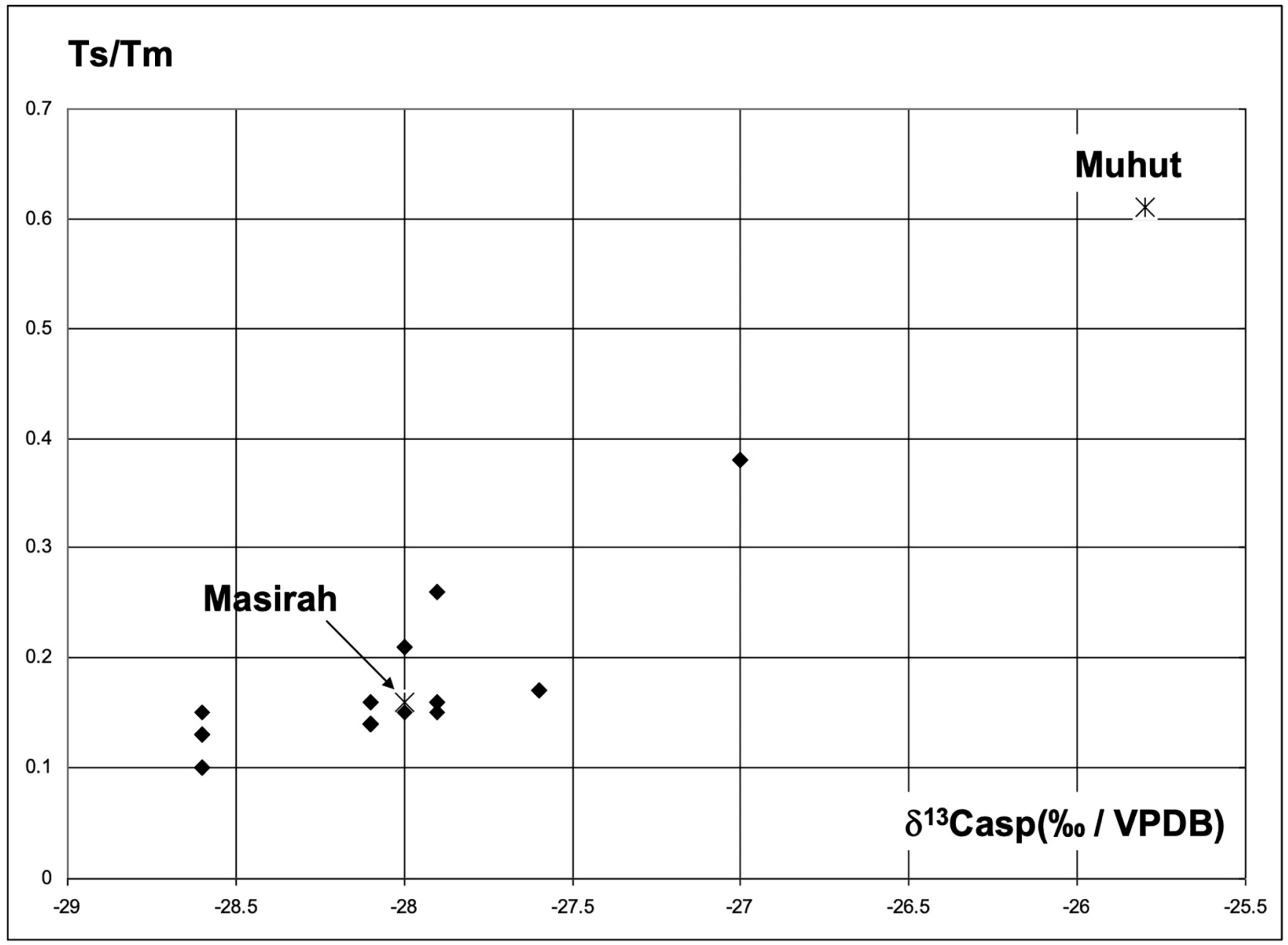

Figure 11. Plot of Ts/Tm vs. $\delta{ }^{13}$ Casp (\%о/VPDB): comparison of Muhut and Masirah to bitumens from Thaj (Saudi Arabia). 


\section{$18 \alpha(\mathrm{H})$-oleanane/C30 $\alpha \beta$-hopane}

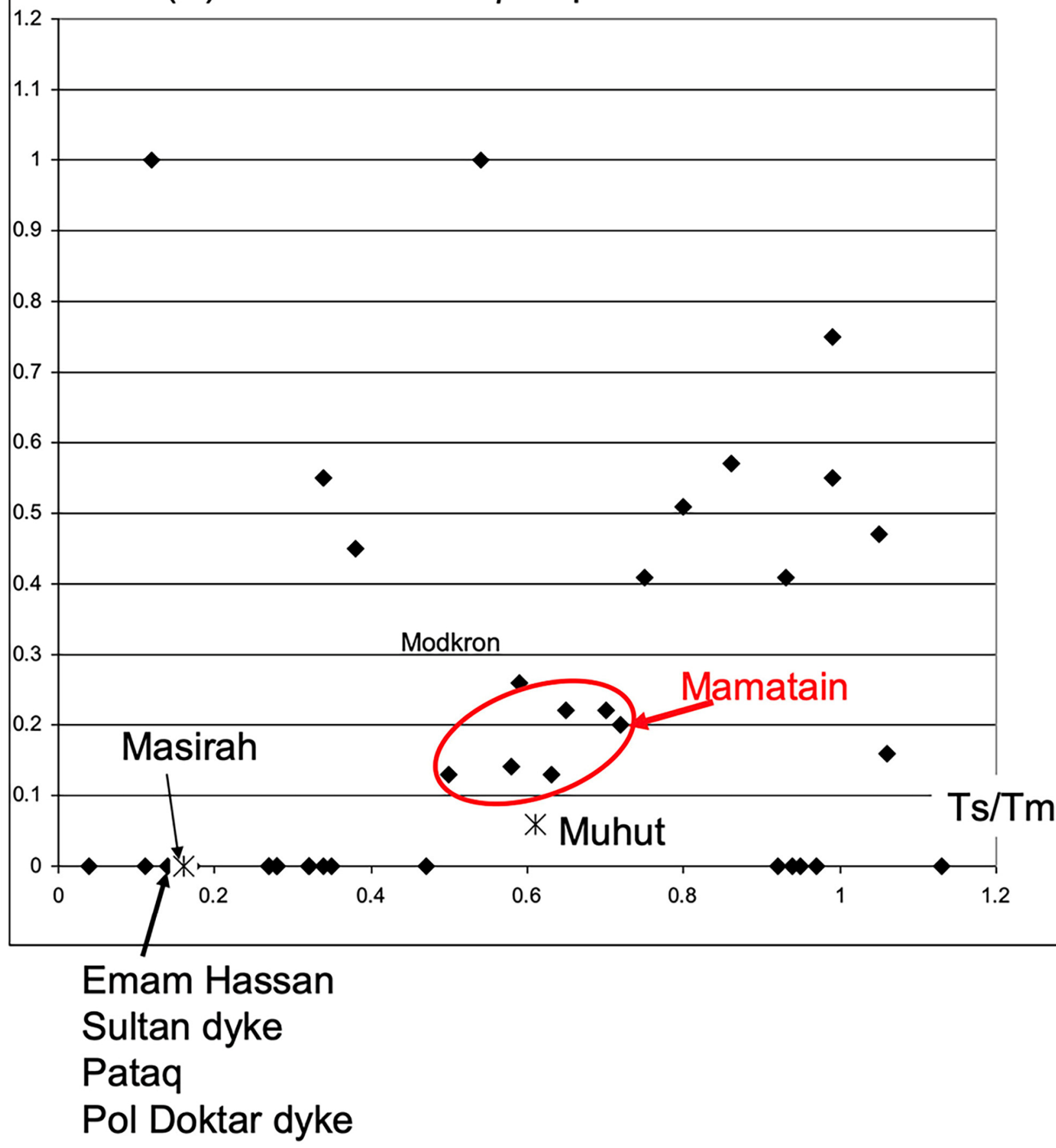

Figure 12. $18 \alpha(\mathrm{H})$-oleanane/C $30 \alpha \beta$-hopane vs. Ts/Tm: comparison of Muhut and Masirah bitumens to oil seeps of Iran.

\section{Conclusions}

The black substance on the outside of the Muhut jar and the black crust coating the inside of the Masirah torpedo jar were bitumen that originated from southwest Iran. The Muhut bitumen is likely to have come from Khuzestan Province. The bitumen of Mamatain is the proposed source, with characteristics approaching those of the Muhut bitumen. It is puzzling that an amphora made in Tunisia, which would have travelled to Oman via the Red Sea, would have traces of bitumen from Iran. One possibility is that the bitumen 
was imported from Iran to Oman, a practice that extends back to the Bronze Age. Another might be that the jar was used in the trade between Oman and the Gulf. The bitumen from the Masirah torpedo jar was issued from another area further to the northwest: namely Pol Doktar, Pataq, Emam Hassan, Sultan dyke in the Kermanshah Province. This evidence appears consistent with the findings of other similar studies of torpedo jars (Figure 13).

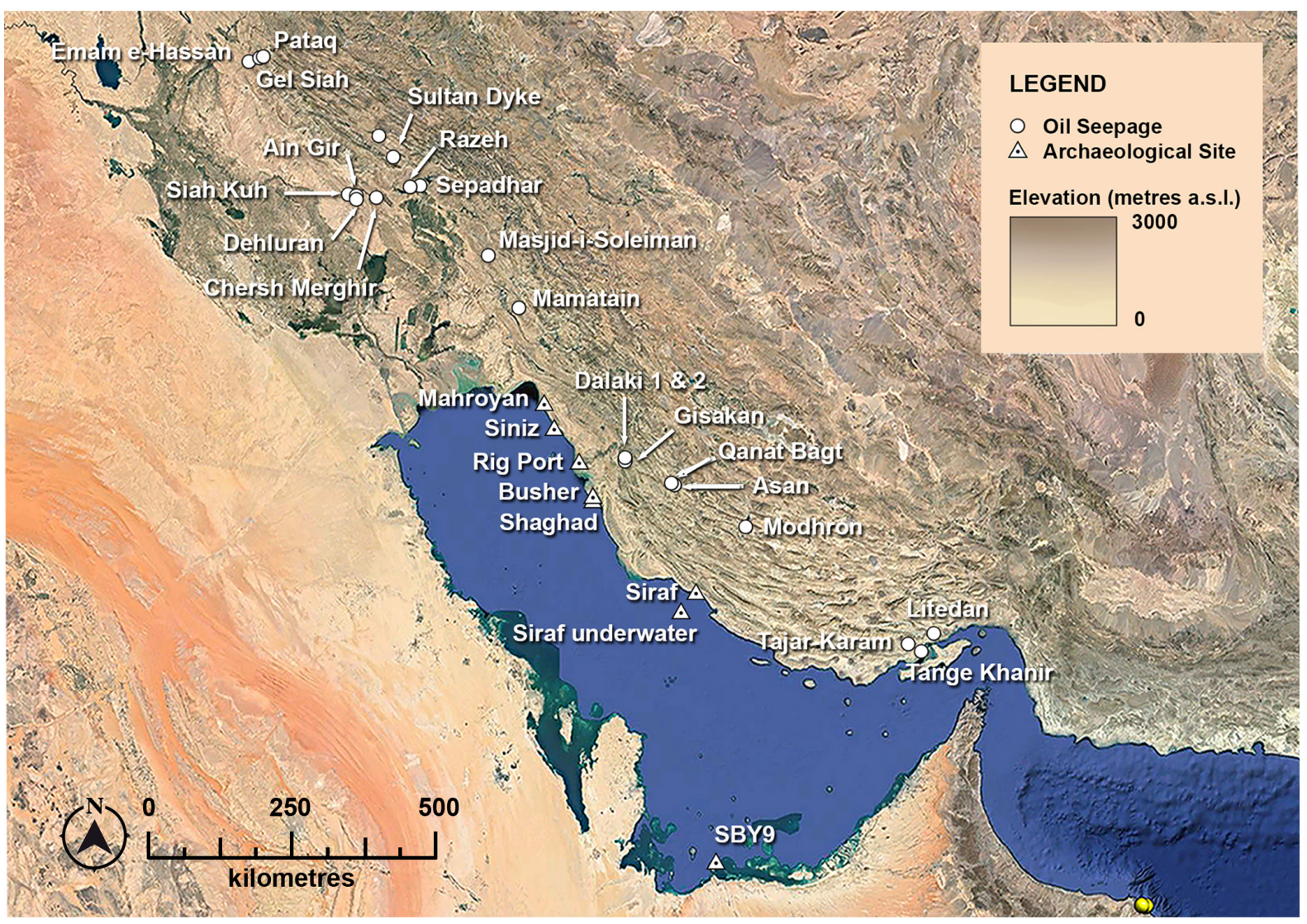

Figure 13. Map of oil seeps analysed in Iran (modified Google Earth image).

Author Contributions: Formal analysis, J.C., M.H.E. and R.B.J.; Funding acquisition, S.P.; Project administration, T.V.; Software, A.Z. All authors have read and agreed to the published version of the manuscript.

Funding: This research received no external funding.

Institutional Review Board Statement: Not applicable.

Informed Consent Statement: Not applicable.

Acknowledgments: The authors are indebted to Rivik Balvally and Prathap Chandran, who provided bitumen samples from torpedo jars from sites in India used as references in the paper. Patrick Couser provided valuable analysis of the volumes of the torpedo jars. We would also like to thank the Ministry of Heritage and Tourism, especially His Excellency Salim Almahruqi the Minister, Sultan al-Bakri, and Khamis al-Asmi for their assistance in providing the samples from Masirah and Muhut. We also thank the Fine Arts Department and The Underwater Archaeology Unit of the Ministry of Culture, Thailand, for use of the data from the bitumen from the Phanom-Surin shipwreck.

Conflicts of Interest: The authors declare no conflict of interest. 


\section{References}

1. Connan, J.; Priestman, S.; Vosmer, T.; Komoot, A.; Tofighian, H.; Ghorbani, B.; Engel, M.H.; Zumberge, A.; van de Velde, T. Geochemical analysis of bitumen from West Asian torpedo jars from the c.8th century Phanom-Surin shipwreck in Thailand. J. Archaeol. Sci. 2020, 117, 105111. [CrossRef]

2. Connan, J.; Carter, R.; Crawford, H.; Tobey, M.; Charrié-Duhaut, A.; Jarvie, D.; Albrecht, P.; Norman, K. A comparative geochemical study of bituminous boat remains from H3, As-Sabiyah (Kuwait), and RJ-2, Ra's al-Jinz (Oman). Arab. Arch. Epig. 2005, 16, 21-66. [CrossRef]

3. Connan, J.; Carter, R.A. geochemical study of bituminous mixtures from Failaka and Umm-an-Namel (Kuwait), from the Early Dilmun to the Early Islamic period. Arab. Arch. Epig. 2007, 18, 139-181. [CrossRef]

4. Connan, J. Technical Report on the Comparative, Compositional and Isotopic Analysis of the H3 Bitumen. In Maritime Interactions in the Arabian Neolithic: Evidence from H3, As-Sabiyah, an Ubaid-Related Site in Kuwait; Carter, R., Crawford, H., Eds.; American School of Prehistoric Research Monograph Series: Boston, MS, USA; Brill: Leiden, The Netherlands, 2010; Appendix II; pp. 261-287.

5. Kennet, D. Sasanian and Islamic Pottery from Ras al-Khaimah: Classification Chronology and Analysis of Trade in the Western Indian Ocean; British Archaeological Reports (International Series), 1248, Society for Arabain Studies Monographs 1; Archeopress: Oxford, UK, 2004.

6. Carter, R. Ceramics of the Qatar National Museum. A Report and Catalogue. Unpublished Report, Oxford Brooks Archaeology and Heritage; 2011. Available online: https:/ / www.academia.edu/700174/Ceramics_of_the_Qatar_National_Museum. (accessed on 19 August 2021).

7. Empereur, J.-Y. Observations sur l'Amphore "Letaconnoux". In Hommages à Jean Leclant; Institute français de archéologie orientale: Cairo, Egypt, 1993.

8. Combès, J.-L.; Louis, A. Les Potiers de Djerba, Centre des Arts et Traditions Populaires, Tunis; Secrétariat d'État aux Affaires Culturelles et à l'Information: Tunis, Tunisia, 1967.

9. Peacock, D.; Williams, D.; James, S. Bitumen as ships' ballast and the Roman incense trade. In Food for the Gods, New Light on the Ancient Incense Trade; Peacock, D., Williams, D., Eds.; Oxbow Books: Oxford, UK, 2007; pp. 28-70.

10. Al-Shanfari, A.A.B. The Archaeology of Masirah Island, Sultanate of Oman. Ph.D. Thesis, University of Naples Federico II, Naples, Italy, 1987.

11. Weisgerber, G.; Al-Shanfari, A.A.B. Archaeology in the Arabian Sea. Masirah and Al Hallaniyyat Islands; Ministry of Heritage and Culture Sultanate of Oman: Muscat, Oman, 2013.

12. Priestman, S.M.N. Ceramic Exchange and the Indian Ocean. Economy (AD 400-1275). II: Indian Ocean. Pottery Classification; British Museum Research Publication: London, UK, 2021. [CrossRef]

13. Tomber, R.; Spataro, M.; Priestman, S. Early Islamic torpedo jars from Siraf: Scientific analyses of the clay fabric and source of Indian Ocean transport containers. J. Br. Inst. Persian Stud. 2020. [CrossRef]

14. Lischi, S.; Odelli, E.; Perumal, J.L.; Lucejko, J.L.; Ribechini, E.; Mariotti Lippi, M.; Selvaraj, T.; Perla Colombini, M.; Raneri, S. Indian Ocean trade connections: Characterization and commercial routes of torpedo jars. Herit. Sci. 2020, 8, 1-14. [CrossRef]

15. Durand, C. From 'ovoid jars' to 'torpedo jars': Investigations into bitumen-lined transport containers in the Gulf and the Indian Ocean in antiquity (second century BCE-third century CE). Arab. Arch. Epig. 2021, 1-12. [CrossRef]

16. Guy, J. The Phanom Surin shipwreck, a Pahlavi inscription, and their significance for the history of early lower Central Thailand. J. Siam Soc. 2017, 105, 179-196.

17. Chern, Y.S. Various ceramics. In The Belitung Wreck. Sunken Treasures from Tang China; Ward, J., Kotitsa, K., Eds.; Seabed Explorations: Nelson, New Zealand, 2004; pp. 640-655.

18. Simpson, S.J. The land behind Rishahr: Sasanian funerary practices on the Bushehr Peninsula. In Afarin Nameh. Essays on the Archaeology of Iran in Honour of Mehdi Rahbar; Moradi, Y., Ed.; The Research Institute of Cultural Heritage Tourism: Tehran, Iran, 2019; pp. 111-124.

19. Kawamata, M. Telūl Hamediyāt near Gubba and Songor: Part II. Al-Rāfidān 1990, 11, 175-188.

20. Al-Haditti, A.-M.M.A.R. Umm Keshm -Summary report. Mesopotamia 1995, 30, 217-239.

21. Stern, B.; Connan, J.; Blakelock, E.; Jackman, R.; Coningham, R.A.E.; Heron, C. From Susa to Anaradhapura: Reconstructing aspects of trade and exchange in bitumen-coated ceramic vessels between Iran and Sri Lanka from the third to the ninth centuries AD. Archaeometry 2008, 50, 409-428. [CrossRef]

22. Blair, A.; Kennet, D.; al-Duwīsh, S. Investigating an early Islamic landscape on Kuwait Bay: The archaeology of historical Kadhima. Proc. Semin. Arab. Stud. 2012, 42, 13-26.

23. Carter, R.A. Christianity in the Gulf during the first centuries of Islam. Arab. Arch. Epig. 2008, 19, 71-108. [CrossRef]

24. Sasaki, T.; Sasaki, H. 1995 excavations at Jazirat al-Hulayla, Ras al-Khaimah. Bull. Archaeol. Univ. Kanazawa 1996, $23,37-178$.

25. Tofighian, H. Ancient torpedo jars of Iran (Persian Gulf). In Archaeology and Conservation Along the Silk Road; Krist, G., Zhang, L., Eds.; Conference 2016 Postprints; Böhlau Verlag: Köln, Germany, 2018; pp. 63-82.

26. Charpentier, V.; Berger, J.-F.; Crassard, R.; Borgi, F.; Davtian, G.; Méry, S.; Phillips, C.S. Conquering new territories: When the first black boats sailed to Masirah Island. Proc. Semin. Arab. Stud. 2013, 43, 85-98.

27. Blue, L.; al-Jahwari, N.S.; Staples, E.; Giorgio, L.; Croce, P.; Ghidoni, A.; Al Busaidi, A.N.; Belfioretti, L. Maritime footprints: Examining the maritime culture landscape of Masirah Island, Oman, past and present. Proc. Semin. Arab. Stud. 2014, $44,53-68$. 
28. West, N.; Alexander, R.; Kagi, R.I. The use of silicalite for rapid isolation of branched and cyclic fractions in petroleum. Org. Geochem. 1990, 15, 499-501. [CrossRef]

29. Coplen, T.B. Normalization of oxygen and hydrogen isotope data. Chem. Geol. 1988, 72, 293-297. [CrossRef]

30. Coplen, T.B.; Qi, H. Applying the silver-tube introduction method for thermal conversion elemental analyses and a new delta ${ }^{2} \mathrm{H}$ value for NBS 22 oil. Rapid Commun. Mass Spectrom. 2010, 24, 2269-2276. [CrossRef]

31. Coplen, T.B. Guidelines and recommended terms for expression of stable-isotope-ratio and gas ratio measurement results. Rapid Commun. Mass Spectrom. 2011, 25, 2538-2560. [CrossRef]

32. Brand, W.A.; Coplen, T.B.; Vogl, J.; Rosner, M.; Prohaska, T. Assessment of inter-national reference materials for isotope-ratio analysis (IUPAC technical report). Pure Appl. Chem. 2014, 86, 425-467. [CrossRef]

33. Forbes, R.J. Studies in Ancient Technology. Bitumen and Petroleum in Antiquity, 2nd ed.; E.J. Brill: Leiden, The Netherlands, 1964; pp. 1-123.

34. Marschner, R.F.; Wright, H.T. Asphalt from Middle Eastern Archaeological Sites. In Archaeological Chemistry 1, Advances in Chemistry Series; Paléorient:: Chicago, IL, USA,, 1978; pp. 97-112.

35. Connan, J.; Kozbe, G.; Kavak, O.; Zumberge, J.; Imbus, K. The bituminous mixtures at Kavuşan Höyük (SE Turkey) from the end of the 3rd millennium (2000 BC) to the Medieval period (AD 14th century): Composition and origin. Org. Geochem. 2013, 54, 2-18. [CrossRef]

36. Connan, J.; Oates, J. The bitumen of Tell Brak from the Middle Uruk (c.3500 BC) to Late Bronze Age (c.1280 BC). J. Hist. Archaeol. Anthropol. Sci. 2018, 3, 756-769.

37. Brown, K.; Connan, J.; Poister, K.M.; Vellanoweth, R.L.; Zumberge, J.; Engel, M.H. Sourcing archaeological asphaltum (bitumen) from the California Channel Islands to submarine seeps. J. Archaeol. Sci. 2014, 43, 66-76. [CrossRef]

38. Daneels, A.; Romo de Vivar-Romo, A.; Linares-Jurado, A.; Reyes-Lezama, M.; Tapia-Mendoza, E.; Morales-Puente, P.; CienfuegosAlvarado, E.; Otero-Trujano, F.J. Chemical analysis of bitumen paint on classic period Central Veracruz ceramics, Mexico. J. Archaeol. Sci. Rep. 2018, 17, 657-666. [CrossRef]

39. Faraco, M.; Pennetta, A.; Fico, D.; Eramo, G.; Beqiraj, E.; Muntoni, I.M.; Egidio De Benedetto, G. Bitumen in potsherds from Two Apulian Bronze Age settlements, Monopoli and Torre Santa Sabina: Composition and origin. Org. Geochem. 2016, 93, 22-31. [CrossRef]

40. Rullkötter, J.; Wendish, D. Microbial alteration of $17 \alpha(\mathrm{H})$-hopane in Madagascar asphalts: Removal of C-10 methyl group and ring opening. Geochim. Cosmochim. Acta 1982, 46, 1543-1553. [CrossRef]

41. Seifert, W.K.; Moldowan, J.L.; Demaison, G.J. Source correlation of biodegraded oils. Org. Geochem. 1984, 6, 633-643. [CrossRef]

42. Chosson, P.; Connan, J.; Dessort, D.; Lanau, C. In vitro biodegradation of steranes and terpanes: A clue to understanding geological situations. In Biological Markers in Sediments and Petroleum; Albrecht, P., Moldowan, J.M., Philp, P., Eds.; Prentice Hall: Hoboken, NJ, USA, 1991; pp. 320-349.

43. Chosson, P.; Lanau, C.; Connan, J.; Dessort, D. Biodegradation of refractory hydrocarbon biomarkers from petroleum under laboratory conditions. Nature 1991, 351, 640-642. [CrossRef]

44. Connan, J.; Genç, E.; Kavak, O.; Engel, M.H.; Zumberge, A. Geochemical study of bituminous samples of Kuriki Höyük (SE Turkey) from 4000 BCE to 200 CE: Composition and origin. J. Archaeol. Sci. Rep. 2021. resubmitted (under review). 